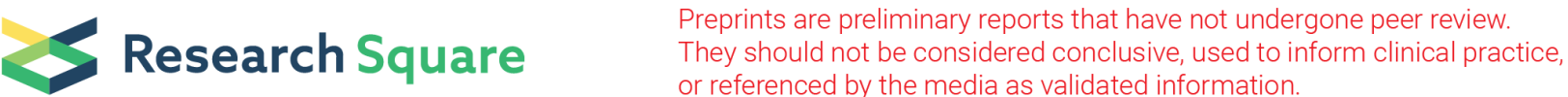

\section{Association Between Gestational Weight Gain in Women With Gestational Diabetes Mellitus and Adverse Pregnancy Outcomes: a Retrospective Cohort Study}

\section{Ping Shi}

Wujing hospital Affiliated with Jiangsu Unversity

\section{Aimin Liu}

Wujing Hospital Affiliated with Jiangsu Unversity

Xiaoyan Yin ( $\square$ yinxiaoyancz@126.com )

Wujin Hospital Affilated with Jiangsu Unversity https://orcid.org/0000-0002-7872-5736

\section{Research article}

Keywords: Gestational weight gain, Gestational diabetes mellitus, Institute of Medicine guidelines, Adverse pregnancy outcomes

Posted Date: April 1st, 2021

DOI: https://doi.org/10.21203/rs.3.rs-379454/v1

License: (a) (i) This work is licensed under a Creative Commons Attribution 4.0 International License. Read Full License

Version of Record: A version of this preprint was published at BMC Pregnancy and Childbirth on July 14th, 2021. See the published version at https://doi.org/10.1186/s12884-021-03982-4. 


\section{Abstract}

Purpose: To examine the association between gestational weight gain (GWG) in women with gestational diabetes mellitus (GDM) and adverse pregnancy outcomes (APOs).

Methods: This retrospective cohort study enrolled women with GDM and singleton live birth pregnancies who delivered between January 2010 and December 2020. Univariable and multivariable logistic regression analyses were used to determine the association between GWG outside the Institute of Medicine (IOM) guidelines and APOs.

Results: Overall, 1606 women with GDM fulfilled the inclusion criteria. After adjusting for confounders, total GWG above IOM guidelines in pregnancy was associated with an increased risk of caesarean delivery [adjusted odds ratio $(\mathrm{aOR})=1.34,95 \%$ confidence interval $(\mathrm{Cl}): 1.04-1.72]$, hypertensive disorders of pregnancy $(\mathrm{HDP})(\mathrm{aOR}=2.00,95 \% \mathrm{Cl}$ : 1.28-3.12), preeclampsia ( $\mathrm{aOR}=2.06,95 \% \mathrm{Cl}$ : 1.01-3.12), macrosomia (aOR=1.55, 95\% Cl: 1.13-2.13) and LGA $(\mathrm{aOR}=1.83,95 \% \mathrm{Cl}: 1.43-2.10)$, and a decreased risk of premature rupture of membrane (PROM) $(\mathrm{aOR}=0.46,95 \% \mathrm{Cl}$ : $0.36-0.60)$ and preterm birth (aOR=0.35, 95\% Cl: 0.26-0.44); total GWG below IOM guidelines in pregnancy was associated with an increased relative risk of preterm birth (aOR=1.96, 95\% Cl: 1.44-2.66) and SGA (aOR=1.32, 95\% Cl: 1.11-1.50) and a decreased relative risk of macrosomia (aOR=0.35, 95\% $\mathrm{Cl}$ : 0.23-0.53). Further, in both second and third trimesters of pregnancy, GWG above IOM guidelines was found to be associated with a high risk of HDP $(\mathrm{aOR}=2.55,95 \% \mathrm{Cl}: 1.86-3.38 ; \mathrm{aOR}=1.93,95 \% \mathrm{Cl}: 1.08-2.98)$, preeclampsia (aOR=2.28, 95\% Cl: 1.21-3.81; aOR=2.17, 95\% Cl: 1.35-4.37), macrosomia (aOR=1.20, 95\% Cl: 1.02-1.82; aOR=2.02, 95\% Cl: 1.51-2.64) and LGA (aOR=1.65, 95\% $\mathrm{Cl}: 1.36-2.04$; aOR=1.88, 95\% Cl: 1.62-2.18). GWG above IOM guidelines in the third trimester of pregnancy also increased the risk of caesarean delivery ( $\mathrm{aOR}=1.48,95 \% \mathrm{Cl}$ : 1.16-2.34). While GWG below IOM guidelines in both second and third trimesters of pregnancy was associated with a decreased relative risk of macrosomia $(\mathrm{aOR}=0.66$, 95\% Cl: 0.52-0.78; aOR=0.52, 95\% Cl: 0.39-0.63). In addition, GWG below IOM guidelines in the third trimester of pregnancy was associated with an increased relative risk of preterm birth (aOR=1.52, 95\% $\mathrm{Cl}: 1.12-2.05)$ and SGA (aOR=1.21, 95\% Cl: 1.10-1.69).

Conclusion: GWG, outside the IOM guidelines has increased risks of APOs among women with GDM, implying that careful surveillance for GWG during different stages of pregnancy is warranted.

\section{Background}

Gestational diabetes mellitus (GDM) is defined as glucose intolerance commencing during pregnancy and not reaching non-pregnant diabetes levels; it is one of the major risk factors of adverse pregnancy outcomes (APOs) [1, 2]. Previous studies have shown that the diagnosis of GDM was highly associated with a risk of hypoglycemia, hyperbilirubinemia, preeclampsia, and cesarean section. It was also associated with a risk of fetal macrosomia, preterm birth, and large for gestational age (LGA) infants, in addition, women with GDM were shown to be at a risk of long-term obesity and diabetes[3, 4]. In China, the prevalence of GDM is 10\% of pregnancies[5]; however, recent studies have shown that the prevalence of GDM has increased with both obesity and gestational weight gain (GWG) among pregnant women and has been correlated with APOs[6, 7].

GWG, an important antenatal factor, is reportedly associated with APOs[8-10]. According to the 2009 Institute of Medicine (IOM) guidelines, excessive GWG increases the risk of cesarean delivery, hypertensive disorders of pregnancy (HDP), GDM, and LGA infants. On the other hand, insufficient GWG increases the risk of small for gestational age (SGA) infants and preterm births[11-14]. However, studies on the association of GWG with APOs in women with GDM are conflicting[15-18]. Yasuda et al. indicated that excessive GWG in women with GDM was significantly related to increased infant birthweight[19]. Insufficient GWG reportedly increased the incidence of preterm 
birth in women with GDM[20]. Moreover, reduced GWG in women with GDM is associated with more favorable obstetric and neonatal outcomes than adequate or excessive GWG[16, 21]. However, whether inadequate GWG is associated with adverse outcomes in GDM has not been fully elucidated. Additionally, there is limited research on the association of APOs with GDM among the adequate range of GWG at different stages.

Therefore, we conducted a retrospective cohort study of women with GDM to investigate the associations among GWG within, below, or above the IOM guidelines with adverse perinatal outcomes. We also assessed whether inadequate GWG is associated with adverse outcomes in GDM in the second and third trimesters of pregnancy.

\section{Methods}

\section{Study design and population}

The study was conducted at a hospital in Changzhou, Jiangsu, China. We analyzed the data recorded for pregnant women diagnosed with GDM who delivered between January 2010 and December 2020. All pregnant women selfreported their pre-gestational body mass index (ppBMI) and measured their height and weight at the first visit to the hospital. Their weight was then recorded in the electronic medical records during every subsequent antenatal clinical visit to the hospital. According to the following World Health Organization (WHO) classifications for body mass index (BMI), women were classified by their ppBMl: underweight $\left(<18.5 \mathrm{~kg} / \mathrm{m}^{2}\right)$, normal weight $\left(18.5-24.9 \mathrm{~kg} / \mathrm{m}^{2}\right)$, overweight $\left(25-29.9 \mathrm{~kg} / \mathrm{m}^{2}\right)$, or obese $\left(\geq 30 \mathrm{~kg} / \mathrm{m}^{2}\right)$. All pregnant women had their last weight measured at delivery within $24 \mathrm{~h}$ of entry into the labor room. Total GWG was calculated by deducting pre-gestational weight from maternal weight at delivery; the GWG in the second trimester (14-28 weeks) and third trimesters (29+ weeks) was calculated based on the gestational age. The GWG of different stages (total GWG and GWG in the second trimester and third trimesters) was stratified into three categories according to IOM guidelines: within, below, and above the IOM guidelines (IOM recommended total GWG: $12.5-18 \mathrm{~kg}$ for BMI $<18.5 \mathrm{~kg} / \mathrm{m}^{2}, 11.5-16 \mathrm{~kg}$ for BMI $18.5-24.9 \mathrm{~kg} / \mathrm{m}^{2}, 7-$ $11.5 \mathrm{~kg}$ for $\mathrm{BMI} 25-29.9 \mathrm{~kg} / \mathrm{m}^{2}, 5-9 \mathrm{~kg}$ for $\mathrm{BMI} \geq 30 \mathrm{~kg} / \mathrm{m}^{2}$; recommended GWG in second and third trimesters: $0.44-0.58 \mathrm{~kg} /$ week for $\mathrm{BMI}<18.5 \mathrm{~kg} / \mathrm{m}^{2}, 0.35-0.50 \mathrm{~kg} /$ week for BMI $18.5-24.9 \mathrm{~kg} / \mathrm{m}^{2}, 0.23-0.33 \mathrm{~kg} /$ week for BMI $25-29.9 \mathrm{~kg} / \mathrm{m}^{2}, 0.17-0.27 \mathrm{~kg} /$ week for $\left.\mathrm{BMI} \geq 30 \mathrm{~kg} / \mathrm{m}^{2}\right)[22]$.

The inclusion criteria comprised of (a) aged 18 years or older without pre-GDM, pre-gestational hypertension, heart disease, hepatic disease, or renal disease; (b) diagnosed with GDM with singleton pregnancy and live birth; and (c) complete medical records of APOs. The exclusion criteria were as follows: (a) multiple pregnancies; (b) no information on ppBMI or weight during pregnancy; and (c) elective abortion or stillbirth before 22 weeks of pregnancy. A total of 30915 pregnant women delivered at our hospital; 1878 pregnant women with GDM were included after applying the inclusion criteria. However, 272 of them were removed from the study after applying the exclusion criteria (Fig. 1). Finally, 1606 pregnant women with GDM were included for analysis. Data of general information, gestational weight, blood glucose, glycated-hemoglobin level, and APOs were obtained from the institutional medical record system. The APOs consisted of adverse maternal pregnancy outcomes and adverse neonatal outcomes. We examined the following adverse maternal pregnancy outcomes: cesarean delivery, HDP, preeclampsia, intrahepatic cholestasis of pregnancy (ICP), placental abruption, premature rupture of membranes (PROM), postpartum hemorrhage, and fetal distress. Adverse neonatal outcomes examined were preterm birth (before 37 weeks of pregnancy), low birth weight (LBW) $<2500 \mathrm{~g}$, macrosomia with birth weight $\geq 4000 \mathrm{~g}$, neonatal asphyxia, SGA, and LGA.

\section{Diagnosis of GDM}


GDM was diagnosed when any blood glucose value was greater than fasting blood glucose at $5.1 \mathrm{mmol} / \mathrm{L}$ or blood glucose after $1 \mathrm{~h}$ at $10.0 \mathrm{mmol} / \mathrm{L}$ or after $2 \mathrm{~h}$ at $8.5 \mathrm{mmol} / \mathrm{L}$ based on a $75-\mathrm{g}$ oral glucose tolerance test. This was based on the criteria of the International Association of Diabetes and Pregnancy Study Groups[23].

\section{Statistical analysis}

Statistical analysis of all data was completed using SPSS version 23.0 (SPSS, Chicago, IL, USA). Mean \pm standard deviation (SD) was used to describe continuous variables, and categorical data were expressed as proportions ( $\mathrm{n}$ [\%]). The ANOVA test were used to analyze the differences in continuous variables, and Pearson's $\chi 2$ test or Fischer exact test were used to analyze categorical data. Adjusted odds ratios (aORs) with $95 \%$ confidence intervals (Cls) were calculated to express the relative risk of the GWG above or below the IOM guidelines on APOs by multivariable logistic regression after adjusting for potential confounding variables. A p value $<0.05$ (two sided) indicated statistical significance.

\section{Results}

\section{Demographic characteristics of the cohort}

Overall, 1606 women were enrolled according to the inclusion criteria (Fig. 1). The GWG of 560 women (34.9\%) was within the IOM guidelines, 545 (33.9\%) had GWG below IOM guidelines, and 501 (31.2\%) had GWG above the IOM guidelines. The demographic and clinical data of these three groups are summarized in Table 1. The pregnant women in the GWG below IOM guidelines group were significantly older than those in the GWG within and above IOM guidelines group (mean age \pm SD: $33.21 \pm 4.36$ vs $32.75 \pm 4.83$ vs $31.86 \pm 4.58$ years, $P<0.01$ ). The ppBMI in the above IOM guidelines group $\left(23.68 \pm 3.41 \mathrm{~kg} / \mathrm{m}^{2}\right)$ was significantly higher than that in the within $\left(22.72 \pm 3.11 \mathrm{~kg} / \mathrm{m}^{2}\right)$ and below $\left(22.48 \pm 2.62 \mathrm{~kg} / \mathrm{m}^{2}\right)$ IOM guidelines groups. The proportion of overweight and obese women (25.2\%) was highest in the above IOM guidelines group, and women in the below IOM guidelines group had the highest proportion (81.7\%) of normal ppBMI. In addition, there were significant differences in the mode of delivery, maternal education, fasting plasma glucose (FBG), and $2 \mathrm{~h}$ GLU among the three groups. However, there were no significant differences in cesarean history, parity, or in-vitro fertilization in these three groups $(P>0.05)$ (see Table 1$)$. 
Table 1

Characteristics of women with gestational diabetes mellitus stratified by gestational weight gain according to IOM guidelines

\begin{tabular}{|c|c|c|c|c|}
\hline Characteristic & $\begin{array}{l}\text { Within(n= 560) } \\
(34.9 \%)\end{array}$ & $\begin{array}{l}\text { Below }(n=545) \\
(33.9 \%)\end{array}$ & $\begin{array}{l}\text { Above }(n=501) \\
(31.2 \%)\end{array}$ & $P$ value \\
\hline Age & $32.75 \pm 4.83$ & $33.21 \pm 4.36$ & $31.86 \pm 4.58$ & $<0.001$ \\
\hline Pre-pregnancy BMI $\left(\mathrm{kg} / \mathrm{m}^{2}\right)$ & $22.72 \pm 3.11$ & $22.48 \pm 2.62$ & $23.68 \pm 3.41$ & $<0.001$ \\
\hline BMI category [n (\%)] & & & & $<0.001$ \\
\hline Underweight (< 18.5) & $68(12.1)$ & $60(11.0)$ & $37(7.4)$ & \\
\hline Normal weight (18.5-24.9) & 414(73.9) & $445(81.7)$ & $338(67.5)$ & \\
\hline Overweight (25-29.9) & $71(12.7)$ & $37(6.8)$ & 108(21.6) & \\
\hline Obese $(\geq 30)$ & $7(1.3)$ & $3(0.6)$ & 18(3.6) & \\
\hline Maternal education [n (\%)] & & & & 0.002 \\
\hline Low & $2(0.4)$ & $2(0.4)$ & $6(1.2)$ & \\
\hline Medium & 100(17.9) & 76(13.9) & $112(22.4)$ & \\
\hline High & 458(81.8) & $467(85.7)$ & $383(76.4)$ & \\
\hline Caesarean history [n (\%)] & 105(18.8) & $90(16.5)$ & $96(19.2)$ & 0.481 \\
\hline Parity [n (\%)] & & & & 0.869 \\
\hline Primiparous & $330(58.9)$ & $327(60.0)$ & $303(60.5)$ & \\
\hline Multiparous & $230(41.1)$ & $218(40.0)$ & 198(39.5) & \\
\hline IVF [n (\%)] & $51(9.1)$ & $55(10.1)$ & $54(10.8)$ & 0.657 \\
\hline Mode of delivery [n (\%)] & & & & $<0.001$ \\
\hline Vaginal & $325(58.0)$ & $346(63.5)$ & $254(50.7)$ & \\
\hline Cesarean & $235(42.0)$ & $199(36.5)$ & $247(49.3)$ & \\
\hline Gestational age (weeks, mean \pm SD) & $38.16 \pm 2.00$ & $37.49 \pm 2.46$ & $38.61 \pm 1.68$ & $<0.001$ \\
\hline FPG on OGTT (mmol/L) & $5.03 \pm 0.95$ & $5.53 \pm 0.78$ & $5.62 \pm 0.89$ & $<0.001$ \\
\hline 2-h blood glucose on OGTT & $8.83 \pm 1.71$ & $8.72 \pm 1.65$ & $8.49 \pm 1.58$ & $<0.001$ \\
\hline
\end{tabular}

\section{Association of total GWG with APOs among women with GDM}

We analyzed the APOs according to total GWG among women with GDM. In comparison to pregnant women with GWG within the IOM guidelines, women with total GWG above the IOM guidelines had an increased relative risk of cesarean delivery (49.3\% vs 42.0\%; $\mathrm{P}=0.02$; $\mathrm{aOR}=1.34 ; 95 \% \mathrm{Cl} 1.04-1.72)$, HDP (13.0\% vs 6.4\%; $\mathrm{P}<0.01 ; \mathrm{aOR}=2.00$; $95 \% \mathrm{Cl} 1.28-3.12)$, preeclampsia (6.6\% vs $2.7 \%$; $=0.04 ; \mathrm{aOR}=2.06 ; 95 \% \mathrm{Cl} 1.01-3.12)$, macrosomia $(24.6 \%$ vs 
16.1\%; $\mathrm{P}<0.01 ; \mathrm{aOR}=1.55 ; 95 \% \mathrm{Cl} 1.13-2.13)$, and LGA (12.0\% vs 6.4\%; $\mathrm{P}=0.01 ; \mathrm{aOR}=1.83 ; 95 \% \mathrm{Cl} 1.43-2.10)$.

Conversely, they had a decreased relative risk of PROM (29.3\% vs $47.0 \%$; $<<0.01$; aOR $=0.46 ; 95 \% \mathrm{Cl} 0.36-0.60)$ and preterm birth (6.8\% vs $15.9 \%$; $\mathrm{P} 0.01$; $\mathrm{aOR}=0.35 ; 95 \% \mathrm{Cl} 0.26-0.44)$.

Women with total GWG below the IOM guidelines had an increased relative risk of preterm birth (25.3\% vs $15.9 \%$; $\mathrm{P}$ $0.01 ; \mathrm{aOR}=1.96 ; 95 \% \mathrm{Cl} 1.44-2.66)$ and SGA (10.8\% vs 7.3\%; $\mathrm{P}=0.03 ; \mathrm{aOR}=1.32 ; 95 \% \mathrm{Cl} 1.11-1.50)$. However, they had a decreased relative risk of macrosomia (6.1\% vs $16.1 \%$; $<<0.01$; $\mathrm{aOR}=0.35 ; 95 \% \mathrm{Cl} 0.23-0.53$ ). There were no statistically significant differences in the relative risk of ICP, placental abruption, postpartum hemorrhage, fetal distress, and neonatal asphyxia placenta previa among all three groups (Table 2). 
Table 2

Association of adverse pregnancy outcome among gestational diabetes mellitus with IOM guideline on total gestational weight gain

\begin{tabular}{|c|c|c|c|c|c|c|c|}
\hline & \multirow{2}{*}{$\begin{array}{l}\text { Within (n= } \\
560) \\
\begin{array}{l}\text { n(100\%) } \\
\text { (Reference) }\end{array}\end{array}$} & \multicolumn{3}{|c|}{ Below $(n=545)$} & \multicolumn{3}{|c|}{ Above $(n=501)$} \\
\hline & & n (100\%) & $\begin{array}{l}\text { crude OR } \\
(95 \% \mathrm{Cl})\end{array}$ & $\begin{array}{l}\text { Adjusted OR } \\
(95 \% \mathrm{Cl})\end{array}$ & n (100\%) & $\begin{array}{l}\text { Crude OR } \\
(95 \% \mathrm{Cl})\end{array}$ & $\begin{array}{l}\text { Adjusted } \\
\text { OR (95\% } \\
\mathrm{Cl})\end{array}$ \\
\hline $\begin{array}{l}\text { Caesarean } \\
\text { delivery }\end{array}$ & $235(42.0)$ & 199(36.5) & $\begin{array}{l}0.80(0.62- \\
1.01)\end{array}$ & $\begin{array}{l}0.79(0.61- \\
1.01)\end{array}$ & $247(49.3)$ & $\begin{array}{l}1.35(1.06- \\
1.71)^{a}\end{array}$ & $\begin{array}{l}1.34(1.04- \\
1.72)^{\mathrm{b}}\end{array}$ \\
\hline HDP & $36(6.4)$ & $25(4.6)$ & $\begin{array}{l}0.70(0.41- \\
1.18)\end{array}$ & $\begin{array}{l}0.63(0.406- \\
1.11)\end{array}$ & 65(13.0) & $\begin{array}{l}2.17(1.15- \\
3.32)^{b}\end{array}$ & $\begin{array}{l}2.00(1.28- \\
3.12)^{\mathrm{b}}\end{array}$ \\
\hline preeclampsia & $15(2.7)$ & $11(2.0)$ & $\begin{array}{l}0.80(0.35- \\
1.85)\end{array}$ & $\begin{array}{l}0.83(0.35- \\
1.97)\end{array}$ & $33(6.6)$ & $\begin{array}{l}2.30(1.17- \\
4.53)^{\mathrm{b}}\end{array}$ & $\begin{array}{l}2.06(1.01- \\
4.21)^{b}\end{array}$ \\
\hline ICP & 19(3.4) & 18(3.3) & $\begin{array}{l}0.97(0.51- \\
1.87)\end{array}$ & $\begin{array}{l}0.97(0.50- \\
1.87)\end{array}$ & $16(3.2)$ & $\begin{array}{l}0.94(0.48- \\
1.85)\end{array}$ & $\begin{array}{l}0.95(0.48- \\
1.89)\end{array}$ \\
\hline $\begin{array}{l}\text { Abruptio } \\
\text { placentae }\end{array}$ & $16(2.9)$ & $26(4.8)$ & $\begin{array}{l}1.70(0.90- \\
3.21)\end{array}$ & $\begin{array}{l}1.68(0.88- \\
3.21)\end{array}$ & $13(2.6)$ & $\begin{array}{l}0.91(0.43- \\
1.90)\end{array}$ & $\begin{array}{l}0.83(0.39- \\
1.78)\end{array}$ \\
\hline PROM & $263(47.0)$ & $278(51.0)$ & $\begin{array}{l}1.18(0.93- \\
1.49)\end{array}$ & $\begin{array}{l}1.17(0.92- \\
1.48)\end{array}$ & 147(29.3) & $\begin{array}{l}0.47(0.36- \\
0.61)^{a}\end{array}$ & $\begin{array}{l}0.46(0.36- \\
0.60)^{b}\end{array}$ \\
\hline $\begin{array}{l}\text { Postpartum } \\
\text { hemorrhage }\end{array}$ & $50(8.9)$ & $58(10.6)$ & $\begin{array}{l}1.22(0.82- \\
1.81)\end{array}$ & $\begin{array}{l}1.24(0.83- \\
1.85)\end{array}$ & 43(8.6) & $\begin{array}{l}0.96(0.63- \\
1.47)\end{array}$ & $\begin{array}{l}0.90(0.58- \\
1.40)\end{array}$ \\
\hline Fetal distress & 164(29.3) & 152(27.9) & $\begin{array}{l}0.93(0.72- \\
1.21)\end{array}$ & $\begin{array}{l}0.93(0.72- \\
1.22)\end{array}$ & 138(27.5) & $\begin{array}{l}0.92(0.71- \\
1.20)\end{array}$ & $\begin{array}{l}0.94(0.71- \\
1.23)\end{array}$ \\
\hline Preterm birth & $89(15.9)$ & 138(25.3) & $\begin{array}{l}2.39(1.63- \\
2.42)^{a}\end{array}$ & $\begin{array}{l}1.96(1.44- \\
2.38)^{a}\end{array}$ & $34(6.8)$ & $\begin{array}{l}0.39(0.25- \\
0.58)^{a}\end{array}$ & $\begin{array}{l}0.35(0.23- \\
0.44)^{a}\end{array}$ \\
\hline LBW & $14(2.5)$ & $20(3.7)$ & $\begin{array}{l}1.49(0.74- \\
2.97)\end{array}$ & $\begin{array}{l}1.69(0.83- \\
3.41)\end{array}$ & $4(0.8)$ & $\begin{array}{l}0.31(0.10- \\
0.96)\end{array}$ & $\begin{array}{l}0.38(0.21- \\
1.27)\end{array}$ \\
\hline Macrosomia & $90(16.1)$ & $33(6.1)$ & $\begin{array}{l}0.34(0.22- \\
0.55)^{a}\end{array}$ & $\begin{array}{l}0.35(0.23- \\
0.53)^{a}\end{array}$ & 123(24.6) & $\begin{array}{l}1.70(1.25- \\
2.30)^{a}\end{array}$ & $\begin{array}{l}1.55(1.13- \\
2.13)^{\mathrm{b}}\end{array}$ \\
\hline $\begin{array}{l}\text { Neonatal } \\
\text { asphyxia }\end{array}$ & $10(1.8)$ & $9(1.7)$ & $\begin{array}{l}0.92(0.37- \\
2.29)\end{array}$ & $\begin{array}{l}0.96(0.39- \\
2.41)\end{array}$ & $6(1.2)$ & $\begin{array}{l}0.67(0.24- \\
1.85)\end{array}$ & $\begin{array}{l}0.64(0.22- \\
1.83)\end{array}$ \\
\hline SGA & $41(7.3)$ & $59(10.8)$ & $\begin{array}{l}1.43(1.23- \\
1.69)^{a}\end{array}$ & $\begin{array}{l}1.32(1.11- \\
1.50)^{\mathrm{b}}\end{array}$ & $21(4.2)$ & $\begin{array}{l}0.66(0.51- \\
0.87)^{b}\end{array}$ & $\begin{array}{l}0.89(0.69- \\
1.09)\end{array}$ \\
\hline LGA & $36(6.4)$ & $40(7.3)$ & $\begin{array}{l}1.11(0.83- \\
1.60)\end{array}$ & $\begin{array}{l}1.01(0.88- \\
1.47)\end{array}$ & $60(12.0)$ & $\begin{array}{l}1.96(1.56- \\
2.25)^{a}\end{array}$ & $\begin{array}{l}1.83(1.43- \\
2.10)^{\mathrm{b}}\end{array}$ \\
\hline \multicolumn{8}{|c|}{$\begin{array}{l}\text { Multivariate analyses were adjusted for age, pre-pregnancy BMI, maternal education IVF, FPG, 2-h blood glucose. } \\
\text { The results were presented with an adjusted odds ratio, aOR }(95 \% \mathrm{Cl}) \text {; }\end{array}$} \\
\hline \multicolumn{8}{|c|}{$\begin{array}{l}\text { HDP, hypertensive disorders of pregnancy; ICP, intrahepatic cholestasis pregnancy; PROM, premature rupture of the } \\
\text { membranes; LBW, low birth weight; OR, odds ratio; Cl, credibility interval }\end{array}$} \\
\hline \multicolumn{8}{|l|}{ a $P<0.01$} \\
\hline$<0.05, \mathrm{cc}$ & th th & in $I O M$ & line sub & & & & \\
\hline
\end{tabular}




\section{Association of GWG in the second trimester of pregnancy with APOs among women with GDM}

To further evaluate the effect of GWG in the second trimester of pregnancy on APOs among women with GDM, 667 women were included for this analysis. Women with GWG above the IOM guidelines were associated with a higher risk of HDP (15.6\% vs 5.3\%; aOR = 2.55; 95\% Cl 1.86-3.38), preeclampsia (7.5\% vs 2.4\%; aOR = 2.28; $95 \% \mathrm{Cl} 1.21-$ 3.81 ), macrosomia (22.6\% vs $17.7 \%$; aOR $=1.20 ; 95 \% \mathrm{Cl} 1.02-1.82)$, and LGA $(13.1 \%$ vs $6.6 \%$; $\mathrm{aOR}=1.65 ; 95 \% \mathrm{Cl}$ 1.36-2.04) than those with GWG within IOM guidelines.

On the other hand, GDM patients with GWG below the IOM guidelines were associated with a lower risk of macrosomia $(6.6 \%$ vs $17.7 \%$; aOR $=0.66 ; 95 \% \mathrm{Cl} 0.52-0.78)$. There were no statistically significant differences in the relative risk of cesarean delivery, ICP, placental abruption, PROM, postpartum hemorrhage, fetal distress, preterm birth, LBW, neonatal asphyxia, and SGA among all three groups of women with GDM (Table 3). 
Table 3

Association of adverse pregnancy outcome among gestational diabetes mellitus with IOM guideline on gestational weight gain in second trimester of pregnancy

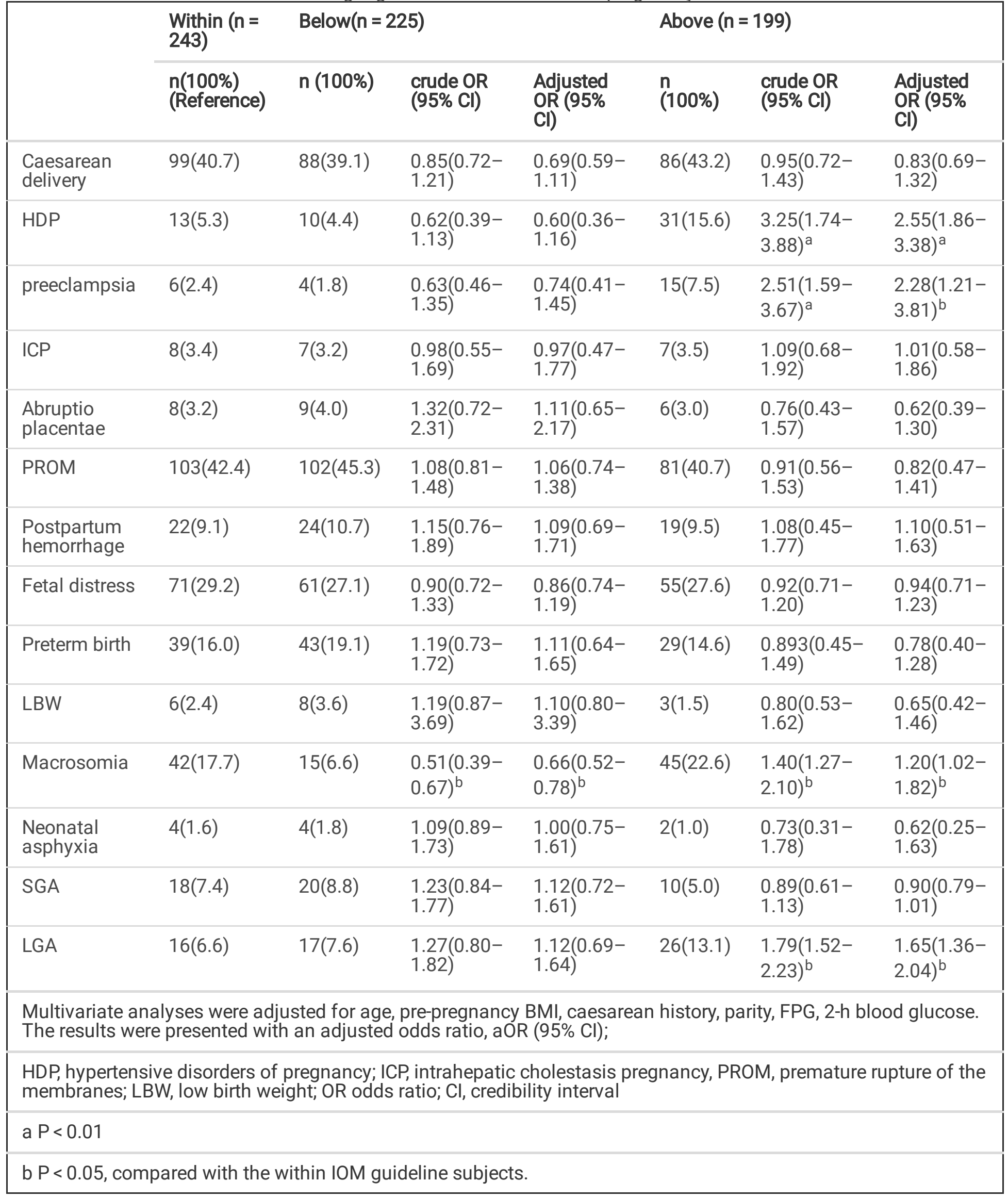




\section{Association of GWG in the third trimester of pregnancy with APOs among women with GDM}

We then analyzed the association between GWG in the third trimester of pregnancy and APOs; 738 women with GDM were included for analysis. Women with GDM with GWG above the IOM guidelines in the third trimester of pregnancy were associated with a significantly increased risk of cesarean delivery $(51.3 \%$ vs $37.0 \% ; \mathrm{P}=0.02 ; \mathrm{aOR}=1.48 ; 95 \% \mathrm{Cl}$ 1.16-2.34), HDP (15.6\% vs 5.3\%; $\mathrm{P}=0.01 ; \mathrm{aOR}=1.93 ; 95 \% \mathrm{Cl} 1.08-2.98)$, preeclampsia $(10.1 \%$ vs $1.9 \% ; \mathrm{P}=0.02 ; \mathrm{aOR}$ $=2.17 ; 95 \% \mathrm{Cl} 1.35-4.37)$, macrosomia (27.3\% vs 17.4\%; $\mathrm{P}<0.01 ; \mathrm{aOR}=2.02 ; 95 \% \mathrm{Cl} 1.51-2.64)$, and LGA (14.7\% vs $6.5 \% ; \mathrm{P}=0.03 ; \mathrm{aOR}=1.88 ; 95 \% \mathrm{Cl} 1.62-2.18)$. This group was also associated with a significantly decreased risk of PROM (30.8\% vs 49.2\%; $P=0.02 ; \mathrm{aOR}=0.51 ; 95 \% \mathrm{Cl} 0.40-0.67)$ and preterm birth $(4.2 \%$ vs $15.5 \% ; \mathrm{P}=0.02 ; \mathrm{aOR}=$ $0.51 ; 95 \% \mathrm{Cl} 0.37-0.72)$.

GDM patients with GWG below the IOM guidelines were associated with a significantly increased risk of preterm birth (32.2\% vs 15.5\%; $\mathrm{P}=0.01$; $\mathrm{aOR}=1.52 ; 95 \% \mathrm{Cl} 1.12-2.05)$ and SGA $(12.4 \%$ vs $6.9 \% ; \mathrm{P}=0.04 ; \mathrm{aOR}=1.21 ; 95 \% \mathrm{Cl} 1.10-$ 1.69). This group was also associated with a significantly decreased risk of macrosomia (5.7\% vs $17.4 \%$; $P<0.01$; $\mathrm{aOR}=0.52 ; 95 \% \mathrm{Cl} 0.39-0.63)$ (Table 4). 
Table 4

Association of adverse pregnancy outcome among gestational diabetes mellitus with IOM guideline on gestational weight gain in third trimester of pregnancy

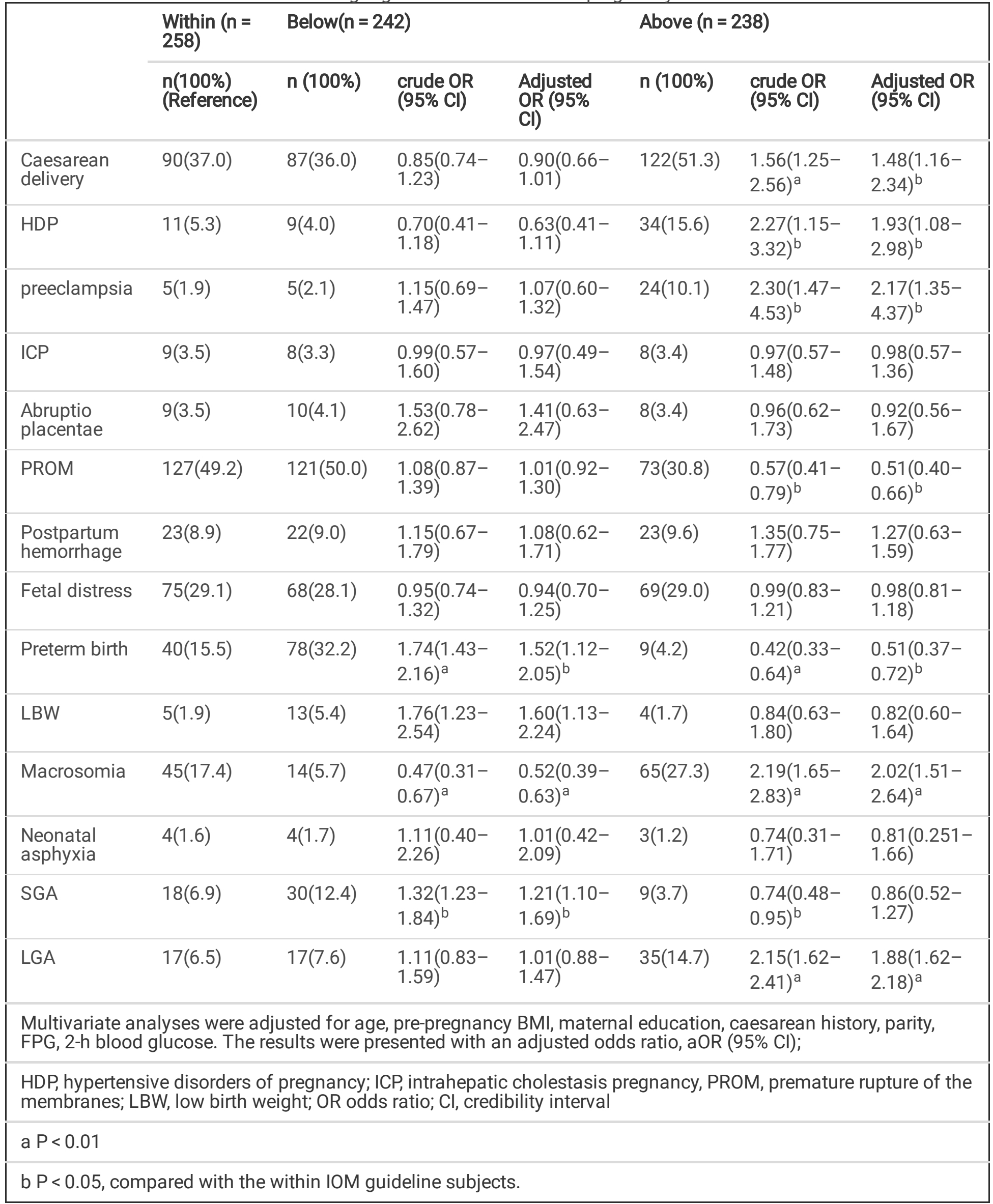




\section{Discussion}

GDM and GWG have been previously reported to be associated with APOs[24, 25]. Considering the conflicting data regarding the relationship between inadequate GWG and APOs in women with GDM and the limited research on the association of the adequate range of GWG at different stages with APOs in GDM, we conducted a retrospective analysis among 1606 pregnant women with GDM. We showed the association between IOM guidelines for GWG, both in total and in the second and third trimesters of pregnancy, and APOs in women with GDM. In the present study, $33.9 \%$ of GDM women presented with a GWG below the IOM guidelines, and 31.2\% presented with a GWG above the IOM guidelines. In previous studies, the rates of insufficient GWG (29.6\%) and insufficient weight gain (12.5\%) were found to be lower than our results $[13,20]$. This variation may be due to rigorous lifestyle improvements, including nutritional therapy and exercise, leading to a leaner population in our study.

We then analyzed the associations of APOs with total GWG in women with GDM during pregnancy. Our results found that total GWG above the IOM guidelines increased the risk of LGA, macrosomia, cesarean delivery, HDP, and preeclampsia. Our findings were in agreement with several previous reports[24, 26-28]. Gou et al. showed that excessive GWG increased the OR for LGA and macrosomia[20]. Komem et al. demonstrated that total GWG above the IOM guidelines is related to cesarean delivery and LGA in women with GDM[24]. Furthermore, Cheng et al. performed the largest trial to date to retrospectively analyze data among women with GDM, which showed a remarkable risk for cesarean delivery, macrosomia, and LGA among women with GWG above the IOM guidelines[29]. However, Scifres et al. reported that women with both excessive GWG and insufficient GWG had a higher risk for macrosomia, which may be due to a different grouping method[30]. In addition, Cheng et al. showed that women with GWG above the IOM guidelines had a high risk of preterm birth[29]. Huang et al. found that, in general, pregnant women with both insufficient and excessive GWG had a higher risk for preterm birth[13]. In the present study, we showed that pregnant women with total GWG above the IOM guidelines had a lower risk of preterm birth, while pregnant women with total GWG below the IOM guidelines had an increased relative risk of preterm birth. These findings suggest that reasonable GWG among women with GDM may shorten the incidence of preterm birth. In concordance with other reports, our results also showed that women with total GWG below the IOM guidelines had a decreased relative risk of macrosomia, with an increased relative risk of preterm birth and SGA[16, 20,21]. In contrast, Gou et al. showed that insufficient GWG did not increase the risk for SGA[20].

Recent studies reported the influence of GWG in the second and third trimesters of pregnancy on the incidence of APOs[31, 32]. For example, Bouvier et al. found that women with GWG above the IOM guidelines had an increased relative risk of HDP, cesarean delivery, macrosomia, LGA, and hypoglycemia in the second and third trimesters of pregnancy[31]. Wu et al. calculated GWG ranges using receiver operating characteristic (ROC) curve analysis (ROC targets) in a retrospective cohort study of women with GDM in Shanghai, China. They showed that ROC targets that provide better GWG guidelines during the second and third trimesters could improve pregnancy outcomes[33]. However, studies on the association of GWG in the second and third trimesters in women with GDM with APOs are limited. Thus, in the present study, we further analyzed the effect of IOM guidelines for GWG in the second and third trimesters of pregnancy on APOs among women with GDM. Our results showed that GWG above the IOM guidelines in the second and third trimesters of pregnant women with GDM was associated with a higher risk of HDP, preeclampsia, macrosomia, and LGA. LGA has been reported to be associated with excessive weight gain in the second trimester of women with GDM in a previous Brazilian cohort study by Drehmer et al., which confirms the results of our study[34]. Drehmer et al. also found that insufficient weight gain was associated with SGA. In another retrospective observational study in India, Kashyap et al. found that pregnant women who had poor rates of weight gain in the second trimester were at an increased risk of SGA[35]. However, in our study, there were no statistically significant differences in the relative risk of SGA in the below or above IOM guidelines group. In addition, we found 
that women with GWG above the IOM guidelines in the third trimester of pregnancy were associated with a significantly decreased risk of preterm birth. However, our findings showed that women with total GWG below the IOM guidelines were associated with a significantly increased risk of preterm birth, which is in contrast with a previous report[34]. The underlying mechanisms for the link between excessive pregnancy weight gain and preterm delivery remain unclear. The inconsistency may be due to the different study populations and the adjusted confounding variables. Our findings on the relationship between APOs among women with GDM and IOM guidelines for GWG in the second and third trimesters may influence clinical practitioners to pay more attention to the control of GWG.

The study has several strengths. First, this study included a relatively large sample size and we adjusted for confounding factors to ensure reliable assessments. Second, we comprehensively analyzed the associations between IOM guidelines for GWG both in total and in the second and third trimesters of pregnancy with APOs in women with GDM, which has rarely been researched previously.

Our study however had several limitations. First, this study was limited due to the retrospective design. Second, some unmeasured confounders including smoking, diet, physical activity, and other factors were not assessed; therefore, the influence of these factors on APOs could not be explored. Third, since our study did not record weight when GDM was diagnosed, we did not investigate the influence of GWG on APOs specifically after the diagnosis of GDM.

In conclusion, our research suggests that GWG above and below the IOM guidelines, both in total and in the second and third trimesters of pregnancy, is a risk indicator for adverse obstetric outcomes in women with GDM. These findings suggest that it is essential to not only maintain an adequate total GWG during pregnancy, but also in the second and third trimesters among pregnant women with GDM. We hope to encourage physicians to deal with GWG using the IOM guidelines and to trigger intervention when it is required, which should help to reduce APOs. Prospective multicenter clinical investigations will be needed to elucidate the potential role of GWG in APOs among women with GDM.

\section{Declarations}

\section{Ethics approval}

The study was approved by the Hospital Ethical Review Committee; informed consent was not required from the women included in the analysis due to the retrospective design of the study.

\section{Conflict of Interest}

The authors declare that they have no conflict of interest.

\section{Availability of data and materials:}

The data that support the findings of this study are available on request from the corresponding author. The data are not publicly available due to privacy or ethical restrictions.

\section{Author contributions}

PS developed the protocol and project, collected and analyzed the data, drafted and substantively revised the work. AL collected data, analyzed the data and helped draft the work. XY developed the protocol and project, edited the manuscript and substantively revised the work. All authors gave final approval of the submitted version to be published. 


\section{References}

1. Spaight C, Gross J, Horsch A, Puder JJ: Gestational Diabetes Mellitus. Endocrine development 2016, 31:163-178.

2. Colagiuri S, Falavigna M, Agarwal MM, Boulvain M, Coetzee E, Hod M, Meltzer SJ, Metzger B, Omori Y, Rasa I et al: Strategies for implementing the WHO diagnostic criteria and classification of hyperglycaemia first detected in pregnancy. Diabetes research and clinical practice 2014, 103(3):364-372.

3. Wendland EM, Torloni MR, Falavigna M, Trujillo J, Dode MA, Campos MA, Duncan BB, Schmidt MI: Gestational diabetes and pregnancy outcomes--a systematic review of the World Health Organization (WHO) and the International Association of Diabetes in Pregnancy Study Groups (IADPSG) diagnostic criteria. BMC pregnancy and childbirth 2012, 12:23.

4. Yu W, Wu N, Li L, OuYang H, Qian M, Shen H: A Review of Research Progress on Glycemic Variability and Gestational Diabetes. Diabetes, metabolic syndrome and obesity : targets and therapy 2020, 13:2729-2741.

5. Shang M, Lin L, Ma L, Yin L: Investigation on the suitability of the International Association of Diabetes and Pregnancy Study Group diagnostic criteria for gestational diabetes mellitus in China. Journal of obstetrics and gynaecology : the journal of the Institute of Obstetrics and Gynaecology 2014, 34(2):141-145.

6. Vinturache A, Moledina N, McDonald S, Slater D, Tough S: Pre-pregnancy Body Mass Index (BMI) and delivery outcomes in a Canadian population. BMC pregnancy and childbirth 2014, 14:422.

7. Aune D, Sen A, Henriksen T, Saugstad OD, Tonstad S: Physical activity and the risk of gestational diabetes mellitus: a systematic review and dose-response meta-analysis of epidemiological studies. European journal of epidemiology 2016, 31(10):967-997.

8. Blomberg M: Maternal and neonatal outcomes among obese women with weight gain below the new Institute of Medicine recommendations. Obstetrics and gynecology 2011, 117(5):1065-1070.

9. Shin D, Song WO: Prepregnancy body mass index is an independent risk factor for gestational hypertension, gestational diabetes, preterm labor, and small- and large-for-gestational-age infants. The journal of maternal-fetal \& neonatal medicine : the official journal of the European Association of Perinatal Medicine, the Federation of Asia and Oceania Perinatal Societies, the International Society of Perinatal Obstet 2015, 28(14):1679-1686.

10. Mohammadi M, Maroufizadeh S: The effect of prepregnancy body mass index on birth weight, preterm birth, cesarean section, and preeclampsia in pregnant women. 2019, 32(22):3818-3823.

11. Siega-Riz AM, Viswanathan M, Moos MK, Deierlein A, Mumford S, Knaack J, Thieda P, Lux LJ, Lohr KN: A systematic review of outcomes of maternal weight gain according to the Institute of Medicine recommendations: birthweight, fetal growth, and postpartum weight retention. American journal of obstetrics and gynecology 2009 , 201(4):339.e331-314.

12. Carreno CA, Clifton RG, Hauth JC, Myatt L, Roberts JM, Spong CY, Varner MW, Thorp JM, Jr., Mercer BM, Peaceman AM et al: Excessive early gestational weight gain and risk of gestational diabetes mellitus in nulliparous women. Obstetrics and gynecology 2012, 119(6):1227-1233.

13. Huang A, Ji Z, Zhao W, Hu H, Yang Q, Chen D: Rate of gestational weight gain and preterm birth in relation to prepregnancy body mass indices and trimester: a follow-up study in China. Reproductive health 2016, $13(1): 93$.

14. Liu L, Hong Z, Zhang L: Associations of prepregnancy body mass index and gestational weight gain with pregnancy outcomes in nulliparous women delivering single live babies. Scientific reports 2015, 5:12863.

15. Berggren EK, Stuebe AM, Boggess KA: Excess Maternal Weight Gain and Large for Gestational Age Risk among Women with Gestational Diabetes. American journal of perinatology 2015, 32(3):251-256. 
16. Gante I, Amaral N, Dores J, Almeida MC: Impact of gestational weight gain on obstetric and neonatal outcomes in obese diabetic women. BMC pregnancy and childbirth 2015, 15:249.

17. Kase BA, Cormier CM, Costantine MM, Hutchinson M, Ramin SM, Saade GR, Monga M, Blackwell SC: Excessive gestational weight gain in women with gestational and pregestational diabetes. American journal of perinatology 2011, 28(10):761-766.

18. Park JE, Park S, Daily JW, Kim SH: Low gestational weight gain improves infant and maternal pregnancy outcomes in overweight and obese Korean women with gestational diabetes mellitus. Gynecological endocrinology : the official journal of the International Society of Gynecological Endocrinology 2011, 27(10):775781.

19. Yasuda S, luchi T, Goto A, Katanoda K: Weight control before and during pregnancy for patients with gestational diabetes mellitus. 2019, 10(4):1075-1082.

20. Gou BH, Guan HM, Bi YX, Ding BJ: Gestational diabetes: weight gain during pregnancy and its relationship to pregnancy outcomes. Chinese medical journal 2019, 132(2):154-160.

21. Miao M, Dai M, Zhang Y, Sun F, Guo X, Sun G: Influence of maternal overweight, obesity and gestational weight gain on the perinatal outcomes in women with gestational diabetes mellitus. Scientific reports 2017, 7(1):305.

22. Guidelines IOMU. Weight Gain During Pregnancy: Reexamining the Guidelines. Washington DC: National Academy of Sciences.; 2009.

23. Metzger BE, Gabbe SG, Persson B, Buchanan TA, Catalano PA, Damm P, Dyer AR, Leiva A, Hod M, Kitzmiler JL et al: International association of diabetes and pregnancy study groups recommendations on the diagnosis and classification of hyperglycemia in pregnancy. Diabetes care 2010, 33(3):676-682.

24. Komem D, Salman L, Krispin E, Arbib N, Bardin R, Wiznitzer A, Hadar E: Gestational weight gain and weight loss among women with gestational diabetes mellitus. Diabetes research and clinical practice 2018, 141:88-97.

25. Viecceli C, Remonti LR, Hirakata VN, Mastella LS, Gnielka V, Oppermann ML, Silveiro SP, Reichelt AJ: Weight gain adequacy and pregnancy outcomes in gestational diabetes: a meta-analysis. Obesity reviews : an official journal of the International Association for the Study of Obesity 2017, 18(5):567-580.

26. Shmueli A, Borovich A, Bergel R, Ovadia T, Hiersch L, Ashwal E, Yogev Y, Aviram A: Gestational weight gain among nutritionally treated GDM patients. The journal of maternal-fetal \& neonatal medicine : the official journal of the European Association of Perinatal Medicine, the Federation of Asia and Oceania Perinatal Societies, the International Society of Perinatal Obstet 2018, 31(9):1177-1181.

27. Restall A, Taylor RS, Thompson JM, Flower D, Dekker GA, Kenny LC, Poston L, McCowan LM: Risk factors for excessive gestational weight gain in a healthy, nulliparous cohort. Journal of obesity 2014, 2014:148391.

28. Egan AM, Dennedy MC, Al-Ramli W, Heerey A, Avalos G, Dunne F: ATLANTIC-DIP: excessive gestational weight gain and pregnancy outcomes in women with gestational or pregestational diabetes mellitus. The Journal of clinical endocrinology and metabolism 2014, 99(1):212-219.

29. Cheng YW, Chung JH, Kurbisch-Block I, Inturrisi M, Shafer S, Caughey AB: Gestational weight gain and gestational diabetes mellitus: perinatal outcomes. Obstetrics and gynecology 2008, 112(5):1015-1022.

30. Scifres C, Feghali M, Althouse AD, Caritis S, Catov J: Adverse Outcomes and Potential Targets for Intervention in Gestational Diabetes and Obesity. Obstetrics and gynecology 2015, 126(2):316-325.

31. Bouvier D, Forest JC, Dion-Buteau E, Bernard N, Bujold E, Pereira B: Association of Maternal Weight and Gestational Weight Gain with Maternal and Neonate Outcomes: A Prospective Cohort Study. 2019, 8(12).

32. Kominiarek MA, Saade G, Mele L, Bailit J, Reddy UM, Wapner RJ, Varner MW, Thorp JM, Jr., Caritis SN, Prasad M et al: Association Between Gestational Weight Gain and Perinatal Outcomes. Obstetrics and gynecology 2018, 
132(4):875-881.

33. Wu JN, Gu WR, Xiao XR, Zhang Y, Li XT, Yin CM: Gestational weight gain targets during the second and third trimesters of pregnancy for women with gestational diabetes mellitus in China. European journal of clinical nutrition 2019, 73(8):1155-1163.

34. Drehmer M, Duncan BB, Kac G, Schmidt MI: Association of second and third trimester weight gain in pregnancy with maternal and fetal outcomes. PloS one 2013, 8(1):e54704.

35. Kashyap H, Sharma D, Gala A, Pratap OT, Murki S: Effect of second trimester and third trimester weight gain on immediate outcomes in neonates born to mothers with gestational diabetes: a retrospective observational study from India. The journal of maternal-fetal \& neonatal medicine: the official journal of the European Association of Perinatal Medicine, the Federation of Asia and Oceania Perinatal Societies, the International Society of Perinatal Obstet 2019, 32(24):4133-4138.

\section{Figures}

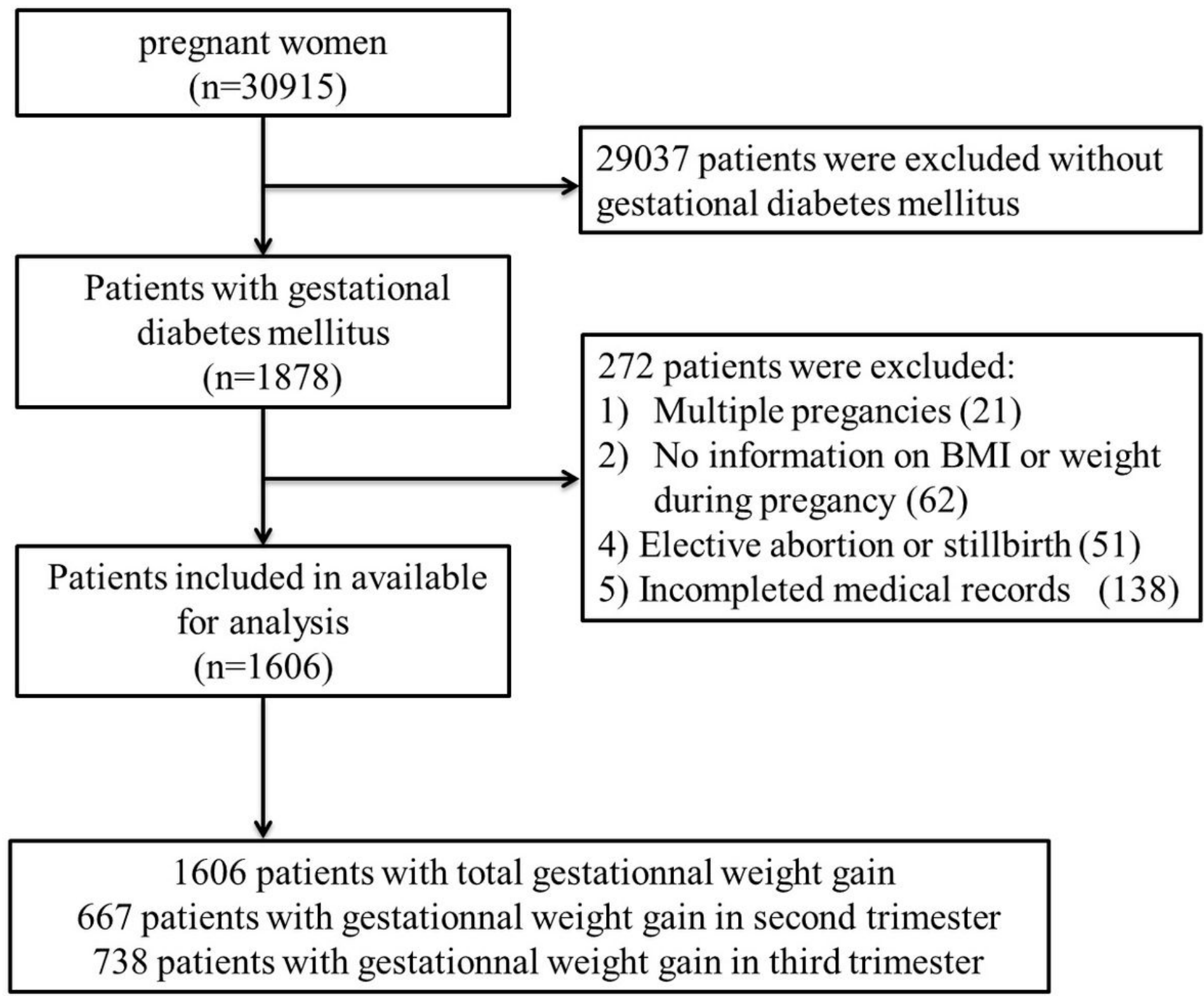


Figure 1

Flowchart of the study 